\title{
The evaluation of public transport safety facilities in developing countries: a case study in Yogyakarta, Indonesia
}

\author{
S. Priyanto \& P. Romadhona \\ Department of Civil and Environmental Engineering, \\ Gadjah Mada University, Indonesia
}

\begin{abstract}
The development of an integrated road safety strategy in a new system of public transport in Yogyakarta, called Trans Jogja, is to address key concerns such as its facilities and safety equipment in three areas; in the bus, in the shelter, and around the shelter. Besides safety for ordinary passengers, safety for disabled persons are also important to be analyzed, since public facilities, such as public transport, should be able to be used by all citizens. Considering that many other modes of public transport in Indonesia do not pay attention to the facilities for disabled persons, this paper aims to analyze whether Trans Jogja did the same things or in contrast, facilitated for disabled persons completely, including their safety. The most affected facilities which make the biggest probability of passengers using the Trans Jogja are shelters, ramps and zebra crossings. Analysis was carried out using a probit model and based on their conditions the probability to use public transport are $42 \%$ for ordinary passengers and $61 \%$ for disabled passengers.
\end{abstract}

Keywords: safety facilities, Trans Jogja, probit model, ordinary passengers, disabled passengers.

\section{Introduction}

The transport system in Yogyakarta, Indonesia, is mostly land-based transportation. Private transport in Yogyakarta is particularly dominated by motorcycles, followed by public transport from all transport modes. The uncontrolled blooming of motor vehicles in Yogyakarta has caused big 
disturbances in traffic flows. On the other hand, according to the Regional Development and Poverty Reduction Program of the Special Province of Yogyakarta [1], the development of (traditional) public transport systems faces some unsolved problems, such as the change from a total of 17 to 23 bus routes that have been hampered by those whose business is public transport.

However, there is no comprehensive strategy in place to address the safety and efficiency of public transport in Indonesia, especially in Yogyakarta; as road accident deaths and injuries are increasing every year. According to POLRI, the State Police of Indonesia (2005) in [1], there were 18,116 traffic accidents which killed 11,451 people, injured 9,253 people with material estimated economic loss of more than 50.000 million rupiah annually. It needs some way to reduce accidents by increasing safety facilities in all vehicles, especially on public transport. One of the ways to help solve the transportation problems is the development of a new public transport system called Trans Jogja. Trans Jogja is a massive public transport system that attempts to solve inefficiency problem of traditional public transport with the operation organization and to contribute to the improvement of the quality life, including safety in Yogyakarta.

Despite all renewed system, safety for the passengers should be the main priority for a modern bus. Safety is one of the major factors that can market the bus system and can gain trust from passengers upon its ability to carry the passengers safely. Safety must be proved within the services, equipment, and facilities. This research begins by outlining the development of an integrated road safety strategy in Trans Jogja to address key concerns, such as the facilities and safety equipment in three places, namely in the bus, in the shelter, and around the shelter. Furthermore, providing access for disabled people to public transport is a crucial part of a quality approach to public transport services.

One means of public transport in land areas is the bus. A bus means a motor vehicle with motive power, except a trailer, designed for carrying more than 10 persons (including the driver), that is used to transport adults and/or children, unless otherwise noted. A bus shall not exceed 102 inches $(2.59 \mathrm{~m})$ in width or 45 feet in length [2]. The bus today represents the most common means of urban transit world-wide. It can be used to cover sprawling areas or can be operated in a linier network, which can be quickly adapted at low cost to meet changing demands. The bus has many applications in local transit which can be summed up in such as as the 'sole' of a public transport service of an entire town, operated as a coordinated service in conjunction with rail vehicles (providing feeder, tangential, or interconnecting service), and provide transport connection between city centres and peripheral communities as express or main trunk lines.

In the existing conditions, the traditional bus as urban public transport in Yogyakarta are already old, more than 10 years on average, and face low credibility of safety. Their age has a big effect on machine performance and smoke that causes pollution and leads to many illnesses. Many seats inside the buses are broken and the floors are dirty. Moreover, there are no ordinary vehicle tests to check the buses condition, the facilities, or the performance.

As a result, many passengers complain about its inconvenient and unscheduled system. The traditional bus in Yogyakarta does not have a 
representative time table and has less safety facilities inside and around the bus. As of now, Yogyakarta does not have comfortable shelters and route limitations for public transport operation in the city. The drivers often drive the buses badly, without paying attention to signs and road markings. This bad attitude may jeopardize the passengers and other road users. All the above situations reflect less guarantee of traditional public transports safety in Yogyakarta.

According to the Transportation State of Yogyakarta [3] Trans Jogja is a new public transport service in Yogyakarta that serves passengers more completely with special buses and special shelters, air conditioners, a scheduled system, and security guards. Trans Jogja which is based on transportation management and in compliance with standard services (such as stop only in the shelter), sets out passengers services and safety, and also uses special bus shelters and automatic ticketing system.

Even though Trans Jogja is the newest public transport in Yogyakarta that has some safety facilities, it still has not fitted out safety facilities in all areas. The shelter ramp in front of the shelter entrance is sometimes useless because it is not covered with disabled requirements. The space inside the shelter is also too tight for disableds movement when they want to enter and exit the shelter. In addition, there are no seat belts for ordinary seats or for disabled people. Moreover, not all Trans Jogja shelters are completed with zebra crossings, although it is very important for passengers as pedestrians.
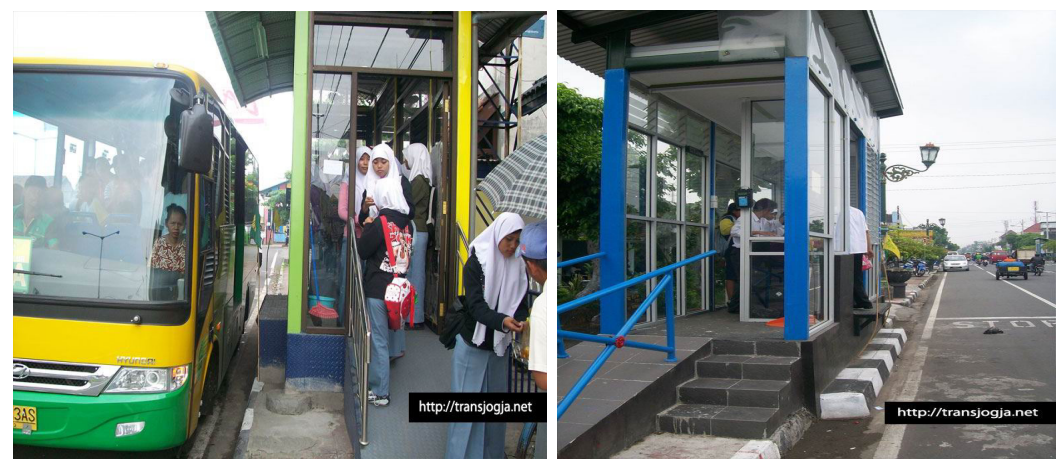

Figure 1: $\quad$ Shelter of Trans Jogja.

\section{Safety facilities for public transport}

There are many ways to prevent accident. One of them is by planning a new road for the bus and designing it with the safety facilities. Indicators of safety aim to assess how far the safety standards applied in the system and facilities, namely:

\subsection{Safety facilities for ordinary passengers}

A bus shelter is used to protect the waiting passengers from pollution and adverse weather conditions, provide some seats for the elderly, some information 
material, and generally provide a convenience for the travelling public. Safety assessment criteria in the shelter includes: service entrance, transfer access, seat belt, safety equipments, driver's skill, traffic signs and marks, zebra crossings.
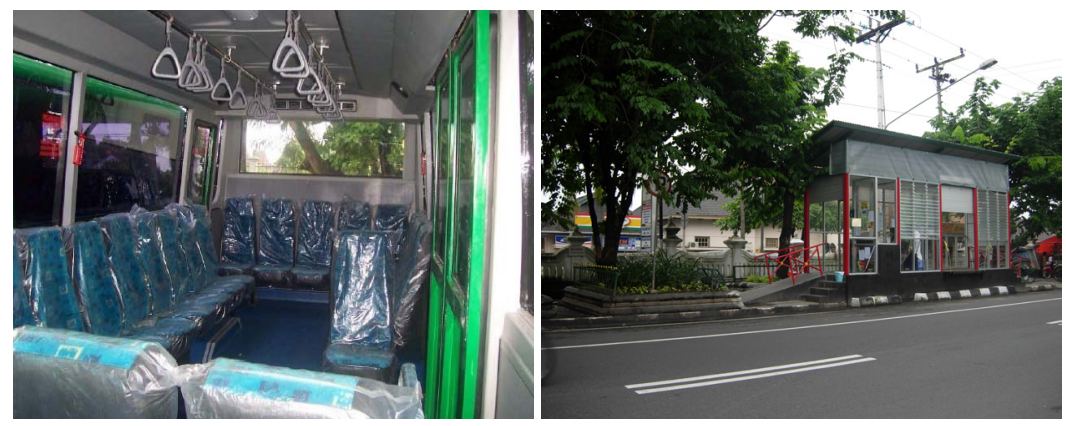

Figure 2: $\quad$ No seat belt and no zebra crossings.

Service entrance is an entry access with entrance gates that leads passengers to the shelter. Service entrance in a modern transport system is usually used for ticket sales. Safety in the service entrance, particularly in the gate entrance, is very important. It should include adequate space movement to enter the shelter.

Moreover, transfer access is built to accompany the passengers from shelter to the bus or from the bus to the shelter safely. These improvements are usually built in front of the shelter to the door of the bus. Transfer access hopefully includes widening the sidewalk and allowing easier access for wheelchairs for disabled passangers loading onto the buses.

Seat belts need to be managed to achieve safety, as they are very useful for ordinary passengers and disabled persons to avoid tragic crashes involving serious intrusion by reducing ejection or contact with the bus interior or other passengers.

The safety equipment [4] is very important inside the bus such as; warning lights to warn the passengers what to do in a dangerous condition such as a fire, machine accident, and so on; warning signs which are located in the window to guide the passenger what they should do to save their life when any accident happens. It usually tells the passenger how to use the safety hammer and extinguisher. In fact, safety hammers, extinguisher, and first aid are very crucial as safety equipments for any accident that may happen. The last, emergency door should be completed with exit sign and emergency words should be installed to guide passengers to exit from the bus in a fast way if an accident happen.

Besides all facilities of the bus, the other main factor for passenger safety is the bus drivers' skills. A good driver should have some abilities as follows: operate a vehicle politely, consider passenger safety, able to communicate with clients who have oral and auditory disabilities, understand and carry out oral and written instructions, assist all passengers phycally, including disabled passengers with dependent living skills, and finally, the bus driver must pass medical exams and a driving test before he is licensed. 
However, it is recommended to apply proper signing and road markings [4] of the whole bus stop areas, even physical restrictions of access. The signs are such as bus shelters, bus lines, no parking for other vehicles, etc. The road marking is suggested to put two small posts $0.5 \mathrm{~m}$ high to physically restrict the entry to the bus stopping area.

Public transportation should facilitate pedestrians and passengers to cross the street safely. Zebra crossings [4] are very important for the pedestrians as bus passengers to take them across the street catching the bus in a shelter and take them from the shelter to their destination opposite the bus stop.

\subsection{Safety facilities for disabled passangers}

Safety facilities must be available for disabled passengers to cover all their needs. Safety facilities for disabled passengers are: shelter ramp, wheelchair space, wheel chair lock-down, and international symbol.

A shelter ramp is a door-to-door shared passengers service available to disabled passengers who are unable to use fixed shelter service. A ramp is a great help for people suffering from different physical disabilities. People suffering from cognitive disabilities and cerebral palsy can make use of handicap ramp for movement. The minimum width of an egress ramp shall not be less than that required for corridors. A provided ramp shall not be less than 36 inches or $0.914 \mathrm{~m}$ (clear width). Maximum ramp slope requirement is similar to that required of ramp width. A ramp required for barrier free accessibility in no case shall have a slope steeper than 1:12. If a steeper ramp slope is allowed, the gravity centre of a person using a wheelchair or walker shifts to the rear and the person along with their mobility aid, will flip over backwards [5].

However, a wheelchair space is a space that must be provided into which a wheelchair-user may maneuver and travel safely, facing the rear of the bus, parallel to its body side, and backed up to a transverse padded backrest. Any additional space(s) for wheelchairs should be located to the rear of the first space (on either side of the bus) so that the first fixed transverse seats are as near as possible to the bus entrance. Moreover, wheelchair space in bus should be completed with wheel chair lock-down which is a special space for disabled passengers to make their wheelchair could not move when they are in the bus. It will be more comfortable for them because they should not need to move in a regular seat as ordinary passenger [6].

Every physically-disabled-passengers vehicle used for the transportation of persons in wheelchairs shall display the international symbol of accessibility in a clearly visible position on the rear of the vehicle and on the front of the vehicle in a position other than on the windshield [7]. The symbol of accessibility required shall be a rectangle, with a height and width of not less than fifteen centimeters and consisting of a symbol in white on a blue background [7].

\section{Methodology}

Based on the conditions of the ordinary passengers as far as research on shelters, around shelters, and on buses, they think using private vehicles is safer because 
they trust in safety by themselves (drive by themselves). The public transport, as the best solution for urban transportation, cannot serve better because the passengers do not feel safe. Therefore, to investigate the willingness of passengers to use public transport, the probit analysis using LIMDEP version 7 software is used [8], by taking data from the stated preference survey. The survey involved both ordinary and disabled passengers.

\section{Modelling of passenger response to safety facilities}

Trans Jogja has already supplied safety facilities for passengers, but some of the standardized facilities are not available. The data are as follows:

Table 1: $\quad$ Safety facilities in Trans Jogja.

\begin{tabular}{|r|l|c|c|}
\hline \multirow{2}{*}{ No } & \multicolumn{1}{|c|}{ Facilities } & \multicolumn{2}{c|}{ Condition } \\
\cline { 3 - 4 } & & Available & Not available \\
\hline \hline I & Shelter & & \\
\hline 1 & Appropriate shelter ramp & $\sqrt{ }$ & \\
\hline 2 & Service entrance & $\sqrt{ }$ & \\
\hline 3 & Safety equipment & $\sqrt{ }$ & \\
\hline 4 & Transfer access & & $\sqrt{ }$ \\
\hline 5 & Wheelchair space & & \\
\hline II & Bus & $\sqrt{ }$ & \\
\hline 1 & Seat belt & $\sqrt{ }$ & \\
\hline 2 & Safety equipment & & $\sqrt{ }$ \\
\hline 3 & Driver skill & $\sqrt{ }$ \\
\hline III & Around Shelter & & \\
\hline 1 & Traffic signing and marking & & \\
\hline 2 & Zebra cross & & \\
\hline
\end{tabular}

Based on Table 1, Variables for the willingness probability model are as follows:

\subsection{Dependent variable}

Dependent variable as bound variable $\left(\mathrm{y}^{*}\right)$ is the passengers willingness probability that closed with bus company effort to upgrade safety facilities and services. Passengers willingness is classified in the following:
a) Totally Satisfied
$=0$
b) Mostly Satisfied
$=1$
c) Somewhat
$=2$
d) Somewhat Dissatisfied
$=3$
e) Very Dissatisfied
$=4$

\subsection{Independent variables}

Based on the theoretical background in modelling, the field observation and passengers opinion (ordinary and disabled), the most safety facilities that really 
need to improve are the following: fare (fare variations for every safety facilities improvement), shelter ramp, wheelchair space, seat belt, and zebra cross.

From those variables, utility equation is the following:

$Y i^{*}=a 0+b 1$ (fare) $+b 2$ (shelter ramp) $+b 3$ (wheelchair space) $+b 4$ (seat belt) $+b 5$ (zebra cross)

\section{Results}

According to observation of respondents taken from the stated preference survey, the model results show as follows:

\subsection{Ordinary passengers}

Model equation for ordinary passengers:

$\mathrm{y}_{\mathrm{i}}^{*}=1.60-0.68$ (Fare) +0.07 (Shelter ramp) +0.58 (Wheelchair space) + 0.33 (Seat Belt) +0.87 (Zebra Cross)

For:

$\begin{array}{lclllll}\mathrm{y}_{\mathrm{i}}=0 & \text { Very Dissatisfied } & : & \text { if } & \mathrm{y}_{\mathrm{i}}{ }^{*} & < & 0 \\ \mathrm{y}_{\mathrm{i}}=1 & \text { Somewhat Dissatisfied } & : & \text { if } & 0 & <\mathrm{y}_{\mathrm{i}}{ }^{*} \leq & 0.68 \\ \mathrm{y}_{\mathrm{i}}=2 & \text { Somewhat } & : & \text { if } & 0.68 & <\mathrm{y}_{\mathrm{i}}{ }^{*} \leq & 1.34 \\ \mathrm{y}_{\mathrm{i}}=3 & \text { Mostly Satisfied } & : & \text { if } & 1.33 & <\mathrm{y}_{\mathrm{i}}{ }^{*} \leq & 2.07 \\ \mathrm{y}_{\mathrm{i}}=4 & \text { Totally Satisfied } & : & \text { if } & & \mathrm{y}_{\mathrm{i}}{ }^{*} \geq & 2.07\end{array}$

Constant value $=1.60$ means if there are no fare increment (fare $=0$ ) and bad safety facilities in overall bus place services (facilities=0) means passengers willingness to use Trans Jogja is 1.60 (Mostly Satisfied it).

\subsection{Disabled passengers}

Model equation for disabled passangers:

$\mathrm{y}_{\mathrm{i}}{ }^{*}=2.38-0.74($ Fare $)+0.06($ Shelter ramp $)+0.68($ Wheelchair space $)+0.22$ (Seat Belt) +1.42 (Zebra Cross)

For:

$\begin{array}{lclllll}\mathrm{y}_{\mathrm{i}}=0 & \text { Very Dissatisfied } & : & \text { if } & \mathrm{y}_{\mathrm{i}}^{*} & < & 0 \\ \mathrm{y}_{\mathrm{i}}=1 & \text { Somewhat Dissatisfied } & : & \text { if } & 0 & <\mathrm{y}_{\mathrm{i}}^{*} \leq & 0.44 \\ \mathrm{y}_{\mathrm{i}}=2 & \text { Somewhat } & : & \text { if } & 0.44 & <\mathrm{y}_{\mathrm{i}}^{*} \leq & 1.21 \\ \mathrm{y}_{\mathrm{i}}=3 & \text { Mostly Satisfied } & : & \text { if } & 1.21 & <\mathrm{y}_{\mathrm{i}}^{*} \leq & 2.83 \\ \mathrm{y}_{\mathrm{i}}=4 & \text { Totally Satisfied } & : & \text { if } & & \mathrm{y}_{\mathrm{i}}^{*} \geq & 2.83\end{array}$

Constant value $=2.38$ means if there are no fare increment (fare $=0$ ) and bad safety facilities in all bus place services (facilities $=0$ ) means passengers willingness to use Trans Jogja is 2.38 (Mostly Satisfied).

\section{Discussion}

\subsection{Analysis results}

The results of analysis of passenger willingness probability to use Trans Jogja can be seen in Tables 2 and 3 . 
Table 2: Analysis results of ordinary passenger willingness probability to use Trans Jogja as scenario.

\begin{tabular}{|c|c|c|c|c|c|c|c|c|c|c|c|}
\hline \multirow{2}{*}{ 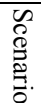 } & \multicolumn{5}{|c|}{ independent variable } & \multirow[b]{2}{*}{$y^{*}$} & \multirow{2}{*}{$\begin{array}{l}\text { prob } \\
\mathrm{yi}=0\end{array}$} & \multirow{2}{*}{$\begin{array}{l}\text { prob } \\
\mathrm{yi}=1\end{array}$} & \multirow{2}{*}{$\begin{array}{l}\text { prob } \\
\mathrm{yi}=2\end{array}$} & \multirow{2}{*}{$\begin{array}{l}\text { prob } \\
\mathrm{yi}=3\end{array}$} & \multirow{2}{*}{$\begin{array}{l}\text { prob } \\
\mathrm{yi}=4\end{array}$} \\
\hline & $\begin{array}{c}\text { far } \\
\mathrm{e}\end{array}$ & ramp & $\begin{array}{l}\text { shelter } \\
\text { space }\end{array}$ & $\begin{array}{l}\text { seat } \\
\text { belt }\end{array}$ & $\begin{array}{l}\text { zebra } \\
\text { cross }\end{array}$ & & & & & & \\
\hline 0 & 0 & 0 & 0 & 0 & 0 & 1.60 & 0.05 & 0.12 & 0.22 & 0.29 & 0.32 \\
\hline 1 & 1 & 0 & 1 & 0 & 0 & 1.50 & 0.1 & 0.14 & 0.23 & 0.28 & 0.28 \\
\hline 2 & 1 & 1 & 0 & 0 & 1 & 1.87 & 0.0 & 0.09 & 0.18 & 0.29 & 0.42 \\
\hline 3 & 2 & 0 & 0 & 1 & 1 & 1.44 & 0.1 & 0.15 & 0.24 & 0.28 & 0.27 \\
\hline 4 & 2 & 1 & 1 & 1 & 0 & 1.22 & 0.1 & 0.18 & 0.25 & 0.26 & 0.20 \\
\hline 5 & 3 & 1 & 0 & 1 & 1 & 0.84 & 0.2 & 0.24 & 0.25 & 0.20 & 0.11 \\
\hline 6 & 4 & 1 & 1 & 1 & 1 & 0.74 & 0.2 & 0.25 & 0.25 & 0.19 & 0.09 \\
\hline
\end{tabular}

Table 3: Analysis results of disabled passenger willingness probability to use Trans Jogja as scenario.

\begin{tabular}{|c|c|c|c|c|c|c|c|c|c|c|c|}
\hline \multirow{2}{*}{ 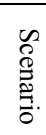 } & \multicolumn{5}{|c|}{ independent variable } & \multirow[b]{2}{*}{$y^{*}$} & \multirow{2}{*}{$\begin{array}{l}\text { prob } \\
\mathrm{yi}=0\end{array}$} & \multirow{2}{*}{$\begin{array}{l}\text { prob } \\
\mathrm{yi}=1\end{array}$} & \multirow{2}{*}{$\begin{array}{l}\text { prob } \\
\mathrm{yi}=2\end{array}$} & \multirow{2}{*}{$\begin{array}{l}\text { prob } \\
\mathrm{yi}=3\end{array}$} & \multirow{2}{*}{$\begin{array}{l}\text { prob } \\
\mathrm{yi}=4\end{array}$} \\
\hline & fare & ramp & $\begin{array}{l}\text { shelter } \\
\text { space }\end{array}$ & $\begin{array}{l}\text { seat } \\
\text { belt }\end{array}$ & $\begin{array}{l}\text { zebra } \\
\text { cross }\end{array}$ & & & & & & \\
\hline 0 & 0 & 0 & 0 & 0 & 0 & 2.3 & 0.01 & 0.02 & 0.10 & 0.55 & 0.33 \\
\hline 1 & 1 & 0 & 1 & 0 & 0 & 2.3 & 0.01 & 0.02 & 0.11 & 0.56 & 0.30 \\
\hline 2 & 1 & 1 & 0 & 0 & 1 & 3.1 & 0.00 & 0.003 & 0.03 & 0.36 & 0.61 \\
\hline 3 & 2 & 0 & 0 & 1 & 1 & 2.5 & 0.01 & 0.01 & 0.07 & 0.52 & 0.38 \\
\hline 4 & 2 & 1 & 1 & 1 & 0 & 1.8 & 0.03 & 0.05 & 0.18 & 0.58 & 0.16 \\
\hline 5 & 3 & 1 & 0 & 1 & 1 & 1.8 & 0.03 & 0.05 & 0.18 & 0.58 & 0.16 \\
\hline 6 & 4 & 1 & 1 & 1 & 1 & 1.8 & 0.04 & 0.05 & 0.20 & 0.59 & 0.15 \\
\hline
\end{tabular}

Based on the willingness probability 'Totally Satisfied' $(y=4)$ as ordinary passengers certain willingness to use Trans Jogja, it can be explained if there are no safety facilities addition (existing) and no increasing fare, ordinary passengers willingness to use Trans Jogja is $31.92 \%$. In addition, the biggest passengers willingness probability to use Trans Jogja is $42.07 \%$ as a result of lower shelter ramp and zebra cross available with fare increment only to of $16 \%$. However, the last scenario when overall safety facilities are available, passengers the willingness probability is the smallest $(9.18 \%)$ as the consequences of most increasing fare $(67 \%)$.

On the other hand, 'Totally Satisfied' $(y=4)$ of disabled passangers certain willingness to use Trans Jogja, it can be explained if there are no safety facilities in addition (existing) and no increasing fare, the disabled passangers willingness to use Trans Jogja is $32.64 \%$. The biggest disabled willingness probability to use Trans Jogja is $61.03 \%$ as a result of lower shelter ramp and zebra cross available with fare increment of $16 \%$. However, the last scenario when all safety facilities are available, the disabled passengers willingness probability is the smallest $(14.46 \%)$ as the consequences of most increasing fare $(67 \%)$.

The most effected facilities which will make biggest probability of passengers to use TransJogja are shelter ramp (lower shelter ramp) and zebra crossing (zebra 
cross-available around all shelters) with a fare increment of $16 \%$. It is $42.07 \%$ willingness probability for ordinary passengers and $61.03 \%$ for disabled. All passengers say that most mark-up (67\%), even though with complete safety facilities, will still not make them use or be more interested to use TransJogja. Better safety facilities for disabled passengers will make them feel comfortable and 'trust' the services. However, a strategy and cooperation from overall parts in many places are definitely needed.

\subsection{Recommendation}

Starting from the shelter, there are many safety facilities that should be installed such as a lower shelter ramp that is especially useful for disabled passangers and a larger shelter space for free movement to all passengers. Besides in the shelter, there are some facilities that should be installed to improve safety facilities in the bus such as seat belt availability, wheelchair lock-down, two way radio, and disabled symbol. However, it needs a 'safe driver guarantee' and vehicle testing inspection as complete ways to build the safety in the bus. Finally, the best advice for a better safety public transport system is transportation management to improve safety facilities without increasing the fare. The management such as stopped fuel subsidized to buy safety facilities and offer free public transport fare or cheaper fare than now.

\section{Conclusions}

From the research concerning the safety facilities for public tansport in Yogyakarta some conclusions can be drawn as follows:

- The safety facilities are much influence by the passangers, both ordinary and disabled, that can be seen from the highest value of passenger willingness which have a relationship with the modelled scenario. This can also be identified by seeing the highest percentage scenario with 'Totally Satisfied' $(y=4)$ of passangers certain willingness to use Trans Jogja for some improvement of safety facilities (based on scenario).

- The most influencing factor for the ordinary passangers is zebra crossings and a shelter ramp, while for disabled passangers it is the same.

- It is recommended to increase the safety facilities with improving the safety facilities around shelters, such as lower shelter ramps and zebra crossing availability.

- The last conclusion is to improve safety facilities without increasing the fare. This way is such as transportation management by stopped fuel subsidized to buy safety facilities and offer free public transport fare or cheaper fares than now.

\section{Acknowledgements}

The authors would like to express their sincere thanks to the WCRU Program in Gadjah Mada University for the support and encouragement to publish this 
paper. Thanks are also extended to the Local Transport Authority of Yogyakarta Special Province who fully supports the evaluation of public transport safety facilities.

\section{References}

[1] Regional Development and Poverty Reduction Program, Development Agenda for DIY Province, Indonesia, 2005.

[2] Black A, Urban Mass Transportation Planning, McGraw-Hill International Edition, USA, 1995.

[3] Transportation State of Yogyakarta, Trans Jogja Specification, Yogyakarta, 2007.

[4] Giannopoulos G A, Bus Planning and Operation in Urban Areas: A practical Guide, Avebury, Greece, 1989.

[5] American with Disabilities Act, Building a Handicap Ramp, www.aboutdisability.com/disability-aids/115-115.html

[6] Disabled Person Transport Advisory, Recommended Specification for LowFloor Buses, www.dptac.gov.uk/pubs/low/index.htm

[7] Federation of Law Societies of Canada, 1990, Vehicles for the Transportation of Physically Disabled Passengers, R.R.O., Reg. 629, Ontario, Canada

[8] Green, W.H., LIMDEP VER. 7.0 User's Manual Revised Edition, Econometric Software Inc., New South Wales, Australia, 1989. 